Acta Universitatis Wratislaviensis No 3920

Anglica Wratislaviensia LVII, Wrocław 2019

DOI: 10.19195/0301-7966.57.1

\author{
Anita Chmielewska \\ ORCID: 0000-0002-3265-4813 \\ University of Warsaw \\ anita.chmielewska2@gmail.com
}

\title{
The Contemporary British-Jewish Family and the Significance of Its Confines in The Innocents, Francesca Segal's Retelling of Edith Wharton
}

\begin{abstract}
After France, Great Britain has the second largest Jewish population in Europe. It is worth taking a closer look at the constantly evolving literature created by this minority. The tendency observed in recent years has been the interest of British-Jewish novelists in the subject of Jewish families from different communities. Some struggle with ultra-Orthodoxy, others are secular, while still others, as in Francesca Segal's debut novel The Innocents, are in between the two extremes. The author decided to raise the subject of Jewish families by rewriting the acknowledged The Age of Innocence by Edith Wharton.
\end{abstract}

Keywords: rewriting, British-Jewish, religious minorities, family

\section{Introduction}

Authors have been retelling popular stories for centuries. There are numerous contemporary rewritings by various authors of classic writers such as, for instance, Jane Austen or Shakespeare. According to L. Plate, authors retell stories for two main reasons: either to re-mythologize or demythologize them (31). She explains that the first reason is "opened up by the promise of further retellings" and the second "seeks to correct" (31). The Innocents, the 2013 literary debut of Francesca Segal, is unmistakably a rewriting of the acclaimed The Age of Innocence by Edith Wharton (Gilbert, "Reality Gaps" 113). According to C. J. Singley, The Innocents and other recent adaptations of Wharton's novels "are responding to a subject in Wharton's fiction that is not always well developed: the importance of family support" (71). This article builds upon Singley's observation and simultaneously 
draws attention to the specificity of the Jewish experience. It has been divided into eight sections discussing the key components in The Innocents that point to the importance of family support in the British-Jewish community.

As Singley notes, "readers familiar with the Age of Innocence will find myriad parallels between Wharton's novel and The Innocents, so precisely does Segal adhere to Wharton's work" (68). In both novels, focalization is led from the perspective of the protagonist: Newland Archer in The Age of Innocence and in the case of The Innocents, Adam Newman. Both men, who are orphans, are favoured by mighty family members and happily engaged to young beautiful women. Both fall in love with their future wife's cousin, who has a questionable reputation, and end up having to give up the romance due to their wife's pregnancy. However, Segal has introduced a number of alternations to the plot of her novel when compared with The Age of Innocence. It appears that these are not random changes, but rather that Segal has carefully arranged them to draw attention to the "clannish society's customs and prejudices" that Wharton heavily criticized (Evron 38). Yet, as this essay demonstrates, in contrast to Wharton, the author of The Innocents emphasizes the constant need for a clan to keep their customs and prejudices. Nonetheless, Segal does not write about a universal clannish group. She is specifically interested in British-Jewish families and emphasizes a notion that the conventions and preconceptions in these families are vital for the survival of the Jewish culture in Great Britain. She engages in the wider discussion taking place on the pages of contemporary British-Jewish fiction, namely, the discussion on the role of family structure in British-Jewish communities.

\section{Jewish families in contemporary British-Jewish literature and culture}

The subject of the Jewish family has been explored by many contemporary British-Jewish writers. Being portrayed as a milieu where Jewish traditions, such as e.g. the Friday night dinner, can be passed on, the Jewish family is also often described as clannish, constricting, and prejudiced against non-Jewish communities. These are the major trends in the rendering of Jewish families on the pages of novels about Orthodox communities, such as The Marrying of Chani Kaufmann by Eve Harris or Naomi Alderman's Disobedience, as well as in the fiction about less observant or even secular families by contemporary British-Jewish authors like Natasha Solomons, Linda Grant, Charlotte Mendelson, Olivia Lichtenstein, or Geremy Gavron.

The preoccupation of contemporary British-Jewish novelists with the subject of the Jewish family seems to be an aftermath of the "dilution of the Jewish identity in the 1990s Britain" (Gilbert, "British-Jewish Writing Today"). The widespread concern about this phenomenon found its outlet in 1993, when The Jewish 
Chronicle, a leading British-Jewish newspaper, published an advertisement that included the following statement: "Jews are not dying but Judaism and Jewish identity are" (qtd. in Kahn-Harris and Gidley, "From Jewish Continuity to Jewish Continuity" 71). The same advertisement claimed that one of the reasons for this process had been the intermarriage of young Jews with people from outside the Jewish community (Kahn-Harris and Gidley, "From Jewish Continuity to Jewish Continuity" 71). Jewish communities in Great Britain of the 1990s were preoccupied with reversing this trend (Kahn-Harris and Gidley, "Contemporary Anglo-Jewish Community Leadership" 176). Consequently, in the last decade of the 20th century, a number of studies were carried out by the British Jewry in order "to develop a more sophisticated self-understanding" (Kahn-Harris and Gidley, "Contemporary Anglo-Jewish Community Leadership" 176). With the turn of the century, the Jewish communities in Great Britain became wary of "the possibility that out-married Jews or their children could develop new forms of Jewish identities" or "of talk of multiple identities" (Kahn-Harris and Gidley, "Contemporary Anglo-Jewish Community Leadership" 176).

Also, another reason for the interest of contemporary British-Jewish writers in the subject of the Jewish family might be the phenomenon of the so-called "new anti-Semitism" that has been observed in Great Britain in the past 20 years (Kahn-Harris and Gidley, "Contemporary Anglo-Jewish Community Leadership" 179). It is defined as "hatred of or discrimination against Jews as a nation", a discrimination that "draws on leftist, anti-imperialist and indeed anti-racist ... themes" (Kahn-Harris and Gidley, "Contemporary Anglo-Jewish Community Leadership" 179 , italics in the original).

Francesca Segal and other British-Jewish writers seem to respond to the fears of the Jewish communities in Great Britain. Their novels explore various controversial themes that can be applied to Jewish families. They are interested, among others, in the impact of religious observance or the lack of it on relations between different members of the family, the controversial theme of adultery and intermarriage, and the topic of bi- and homo-sexuality within an Orthodox community. Many of them renegotiate the long-established roles of women as housewives and men as educators. However, they do not outwardly criticize the clannish family structure, but rather suggest that family members should try to work through their conflicts and stick together.

\section{The settings}

First of all, it should be noticed that Segal is writing specifically about a British- Jewish family rather than an American one, and one that does not belong to any religious 
minority, ${ }^{1}$ but simply to the upper class. The novel suggests that Great Britain now, just like the US in the past, has become a land of immigrants. Nevertheless, Segal does not draw a parallel between the two countries as they are today, but rather between contemporary Britain and the US of the second half of the 19th century, as the Jewish people in The Innocents, just like the characters in The Age of Innocence, do not have long-established ancestry in the place where they live.

It can be also said that The Innocents is a geographical reversal of The Age of Innocence. In Wharton's novel, the newly married Newland and May travel to Europe and in The Innocents, Adam and Rachel decide to spend some time in the US. A possible interpretation would be that, overall, the main message of The Innocents is in a way a suggestion of the reversal of The Age of Innocence. It is also worth drawing attention to the regular journeys that Rachel's family make to Eliat in Israel (Segal 108). What is clearly emphasized here is their sense of Jewishness, understood not only as an attachment to Judaic rituals, but also as an attachment to the land of Israel.

Moreover, The Age of Innocence opens with a scene at the opera, which is a place where one used to go not only to listen to music but also to socialize. Interestingly, The Innocents opens with a synagogue setting. Bearing in mind the parallel structures of the novels, it seems that the settings cannot be coincidental. Apparently, what a synagogue shares with an opera house is the social function. According to Singley, "the substitute setting conveys a sense of ritualized practice and predictability that is essential to Wharton's novel. It also provides a moral weightiness that is present in Wharton's fiction" (69). More obviously, the synagogue setting is inescapably associated with Judaism, which has been the major preserver of Jewish culture throughout the centuries. The characters of Segal's novel seem to strongly associate themselves with religious practices, a function of which is the gathering of family and friends together. Not only do they meet in a synagogue, but they also celebrate the Shabbat, the traditional Jewish marriage ceremony, Purim, or the circumcision ritual (Segal 210, 212, 249-261, 421-436).

\section{The threat of mixed marriages}

The Jewishness of the family is meant to be protected by the strong reluctance of Jewish mothers to marry their sons to non-Jewish women. Part two of both The Age of Innocence and The Innocents opens with the description of the protagonist's wedding ceremony. However, in the case of the latter, there is the added rendering of Adam's mother's reflection on the matrimonial future of her son. He is aware that his mother wouldn't like him to marry a non-Jewish woman: "from the moment

${ }^{1}$ There has been an ongoing discussion on whether Jewish people are a religious, cultural or ethnic minority. In this article, I use the first term. 
he enters secondary school there is a constant anxiety that a blue-eyed Christina or Mary will lure him away from the tribe. ... Somewhere there is a shiksa with designs on her son" (Segal 249, italics in the original). The vocabulary used to express her opinion, as Adam sees it, clearly indicates that she is very critical about him potentially having a non-Jewish bride.

Interestingly, his perspective seems to go in line with his mother's. He explains that "[a]fter all, who does not believe in continuity? Who doesn't fear cultural dispersion, collective forgetting, assimilation?" (Segal 250-251). At the same time, he knows that he is not "required to marry a Jewish girl ... whose mother had for years bumped into one's own mother in Waitrose and who was therefore known and parentally endorsed" but that it is a "simpler belief" (Segal 159). Here, once again, the feeling of cultural separateness of the family is visible, as they do not feel assimilated and they want to protect themselves from being dispersed in the culture of the majority. A culturally uniform family provides an environment in which its traditions can be preserved and passed down.

\section{The stereotypes}

Such a family is also a milieu where one will not face any accusations stemming from cultural stereotypes. A good example is an unpleasant situation that Ziva, Rachel's grandmother once experienced. As it is explained:

Amy Thomas had seen Rachel's grandmother swaddling fairy cakes in napkins and putting the bundles into her handbag. ... The next day Amy Thomas had suggested that Rachel's grandmother probably didn't want to pay for her own cupcakes because Jews didn't like to spend money. (Segal 283)

It appears that Ziva's family could react to such stereotypes about Jews in two totally different ways. Either they could acculturate or they could create a milieu where they would feel safe from accusations based on untrue ideas. They chose the second option and created an ethnically uniform family, which is a realization of such a milieu. Though oppressive, it serves its function: it protects.

However, there is one stereotype that the novel clearly upholds, i.e. the stereotype of an overprotective Jewish mother. As R. Gilbert observes, it is "one of the most notable stereotypes associated with the Jewish woman" "“A Vortex of Contradictory Forces" 125). The stereotype is apparent in the character of Michelle, who is Adam's friend Willa's mother-in-law, in the case of Adam's mother, and Rachel. As Adam explains: "Matthew was not Jewish and therefore did not have a Jewish mother with whom he was required to communicate on an hourly basis" (Segal 101; see also 157-158). Willa's mother-in-law is very similar: "[w]ith Sarah London as her mother-in-law, she would return from every holiday for the rest of her life to find her flat clean, her ironing done, and a pint of milk, a moussaka and a crème brûlée in her fridge" (Segal 154). After her own marriage, Rachel also 
becomes overprotective: "it had begun to feel faintly oppressive. Despite discouragements, Rachel had always called and texted him [Adam] during the day but now the communication was almost hourly" (Segal 293-294). However, what is interesting is the fact that such behaviour is not expected by her family. They would much prefer her to work rather than constantly engage in helping others (Segal 297). In addition, Adam becomes increasingly irritated by her behaviour. The parallel character of May in Wharton's novel does not undergo such a metamorphosis. The question arises about the function of this alteration of May's character that Segal proposes, together with introducing two other Jewish mother figures. In the past "the continuity of Jewish life depended on the mother's commitment to the spiritual health of her loved ones and to the Jewish community in which she lived" (Antler 15). Segal appears to draw attention to this family-bonding role of Jewish mothers that since the 1960s has evolved both in film and in literature into a "troubling creation" of "an image of (the) anxious, overbearing" women (Gilbert, "A Vortex of Contradictory Forces" 126). Though the mothers in The Innocents follow this stereotype, it should be remembered that the novel's central theme is the preserving of the Jewish family structure in contemporary times. What The Innocents thus seem to emphasize is the vital role of the overprotective mothers in the safeguarding of their clannish family milieus.

On the other hand, Olivia, Adam's sister, seems to serve as a contrasting image to the mother figures in the novel. There is no clear parallel character for her in The Age of Innocence. She is a young, liberated intellectual who manifests her non-conformity by wearing original clothes and leaving her hair down. But, despite her taste in fashion and her intellectual achievements, she does not seem to be a rebel when it comes to her family. She does not oppose Ellie's expulsion from the family, nor does she support Adam when it comes to his affair with Ellie. Even more importantly, she seems interested in the history of the Jews. She recommends Rachel's grandmother an exhaustive book on anti-Semitism in England and suggests to Lawrence an article entitled "Wordsworth and the Jews" (Segal 210-211).

\section{The femme fatale figure}

Ellie is much more controversial than Olivia because, although she is obviously the Countess Olenska of The Innocents, she is portrayed differently. J. Jessee notices that Countess Olenska is presented as a dark-haired, oriental temptress, an opposite to the fair May (38). However, the author claims that what Wharton does in her novel is calling "into question the reality of any meaningful distinction between apparently oppositional binaries" (Jessee 37). As Ricard points out, Ellen seems to be presented as a positive change in the New York community (86).

The portrayal of Ellie in The Innocents differs from the one of Ellen in The Age of Innocence. Ellie, in contrast to Ellen, is described with much emphasis as a 
femme fatale figure. The passage that seems to be of particular importance in this regard is the one describing the photograph of Ellie for the Pirelli calendar. In The Age of Innocence, there is no such fragment that would correspond to the following description:

it was a photograph of Ellie, almost life-size, bathed in grey-green shadow and chlorophyllgreen light and looking more extravagantly sensual than he had ever seen her. It was a simple picture. She stood leaning against a tree trunk, her hair long and wet, her body wet and oiled. (Segal 300)

The green light filling the photograph intensifies the association with nature and vegetation. However, what draws attention is the apparent artificiality of the light. Ellie arouses Adam when he sees the picture; she may seem to "belong" to nature, but the artificial light instead of the natural one metaphorically discloses that Ellie's belonging to nature is delusive because it is just a posed, purposefully lit, staged photograph.

Earlier in the novel, in order to speak freely, without the oppressive family, Ellie leads Adam to the forest: "Ellie strode on ahead of him towards a narrow wooden footbridge. The boards were mottled green and slick with damp moss and in the middle of this she sat" (Segal 172). In The Age of Innocence, whenever Countess Olenska and Newland are not in the company of their family or friends, they are surrounded by random people. Neither do they meet in purely natural settings; they are always inside some kind of building. Adam and Ellie are symbolically sheltered by nature, or are even part of it as a couple. Interestingly, the moss present in the fragment is mentioned more than once when describing Ellie. At some point, during one of her meetings with Adam, Ellie is literally following the moss line with her steps:

$[\mathrm{m}]$ oss has darkened the seams between the broad York flagstones; Ellie began to follow one of these cracks with deliberation, walking heel to toe like a tightrope walker. After a few steps, she turned and began to retrace the same slow, careful steps. (Segal 60)

Moss is not necessarily a forest plant, but does not grow in dry places and it is rather thought of in connection with moisture and more generally, water. Interestingly, in many cultures, including the Jewish one, women are very strongly identified with this element. As T. Meacham notices, "whether rites of purification (collective rites) or rites of protection (superstitious acts to protect a person), they were mostly women's responsibilities. Women associated water with life" (208). Following this interpretation, it may be suggested that at the beginning Ellie is associated with life, but with the introduction of the description of the photograph, the falseness of such an impression is exposed. Ellie may surround herself with water and moss but, in the end, what strikes the reader is the artificiality of the nature surrounding her. She will not grow or renew herself.

Ellie is stylized as a femme fatale, an "evil seductress who tempts man and brings about his destruction" (Place 47). In other words, a mysterious woman that 
one may desire but will never create a family with: "Adam began to suspect that she had a different personality for each man she chose to please, slipped on and off as easily as a silk dress" (Segal 124). Countess Olenska, though wearing out-ofplace gowns and behaving in a much more easy-going manner than her relatives, is a femme fatale to a much lesser degree than her counterpart in The Innocents. Ellie, on the other hand, has an unsettling, mysterious aura surrounding her: "[a] small heater glowed on the wall beside her, casting a strange orange light on her skin" (Segal 144). When she tells Adam about her sleeplessness, he answers "it's an illusion" that only she has such problems (Segal 146). Strangely, Adam notices at that moment that " $[\mathrm{h}] \mathrm{e}$ could hear himself prolonging these last words, particularly iloooosion, as if he were doing a voiceover for a haunted house at the fair" (Segal 146 , italics in the original). Even more interestingly, during the same party, Adam thinks that Ellie resembles a warrior, however, not one that would protect, but rather enslave him: "Amazonian, he thought, and it was as if the word had never been so perfectly embodied. She looked like a warrior princess, lifted high again on those impossible driftwood heels and looking down on him" (Segal 145).

\section{The plot endings}

The plot structure of The Innocents, which encompasses a shorter time span than in The Age of Innocence, also draws attention to the subject of family relations. As N. Evron argues, "at the work's [The Age of Innocence] center, is precisely the mutability of tradition and its inevitable capitulation in the face of time and cultural change" (47). In Wharton's novel, the ending clearly points to the fact that things changed after two decades, i.e. the family evolved and got rid of its constraints. Yet, The Innocents ends with the description of Adam's son's circumcision ceremony and there is no further chapter describing the fate of the book's protagonists after this event. The readers are left with the present status quo.

Moreover, circumcision places the family in a long-established tradition. The focus is not on the opening of the family to new ways or allowing people who used to not be welcome in the family to become part of it, but on the preserving of family bonds, which manifests itself in the closing sentence of the book: "[a]s Rachel and Adam approached, hand in hand, he [Lawrence] looked up and Adam caught his eye. Lawrence smiled" (Segal 436). Adam's father-in-law, Lawrence, is the most respected member of the family, the person every relative looks up to and listens to. For him, family is the most important value one should live for: "[t]o Lawrence, there was only ever one thing that was important, and that thing was family. For his own family, Lawrence would cross not only oceans but continents, stratospheres-galaxies, if necessary" (Segal 185). His smile that closes the book gives a very clear message: things have turned out as he wished, his son-in-law's mistress has been successfully isolated from her lover, and Rachel and Adam have 
not separated. Tellingly, instead of being informed about the innovative ways of the new generation, readers are left with a smile of content of an elderly traditionalist for whom his family is the greatest value. The very last sentence of the novel metaphorically suggests that the future fate of the family members in The Innocents will still be determined by the good of their clan and that they will not easily break from its confines.

Lawrence's mission of keeping his family together is reiterated each time that he is mentioned taking photographs of their life. He gathers material that would eternally speak of the togetherness of the family. However, he never captures anything that would cast a shadow on the picture of a perfectly happy group of loving relatives (Segal 204, 436). Interestingly, by the end of the book, what is indicated is Adam's choice to follow and refine Lawrence's strategy: "Adam had increased the resolution on all the cameras, so all these first portraits could be reproduced in brilliant detail, meters wide. Clear enough to preserve every nuance, every moment, every cell" (Segal 436). It seems that Adam decides to join Lawrence in his project of creating a family album that would not tell the whole truth about them, but only the parts that would inspire future generations to continue protecting the structure of this family. Though there are allusions to the visual arts in The Age of Innocence, they do not seem to communicate such meaning. ${ }^{2}$

\section{The coral}

It is also interesting to point out how Segal decided to "expand" the penultimate chapter of The Age of Innocence. The parallel of this chapter in The Innocents is chapter 31. Both end with the protagonist's conversation during which he finds out that his wife is pregnant and that she has successfully made Ellie/Countess Olenska leave the country. However, in The Innocents one more paragraph has been added that closes the chapter:

And there it was. His submarine had blown into a thousand pieces and he could see the whaleno more tiny glimpses through a window, because instead, he was drowning. Ellie was leaving because Rachel had told her. ... Tonight, in that crowded room of friendship and family and history, there had been no secrets ... they all knew, because it was how it worked. And they had all moved together like fronds of coral, to expel the predator. They were shielding Rachel. And no doubt, they thought, they were shielding Adam from himself. (Segal 418)

Adam's family is compared to coral, a colony of animals that by their co-operation throughout many generations create long-lasting structures and protect each other. What seems to be implied by this simile is that such a strategy of survival is a primal instinct of a clan. However, despite this justifiable, fundamental drive to keep each other safe, it may be argued that the words "they thought" in the final sentence of the fragment might indicate that the family is wrong when assuming

\footnotetext{
${ }^{2}$ For more on The Age of Innocence and visual allusions see H. Killoran.
} 
that they are protecting Adam. Nevertheless, bearing in mind that the narration is from Adam's point of view, it appears that The Innocents does not really criticize the confines of strict family rules as Wharton does. It rather considers these structures as something that has long been encoded in nature, that serves a purpose, and so, that it should not be accused of injustice. In The Age of Innocents, the closest to such a description of the family is "the tribe" (Wharton 12, 31, 182, 337, 338). Nonetheless, this description does not bring such strong associations with primal instincts as "the coral" does.

\section{The names}

In Segal's novel, the comments on the significance of the family structure appear to be also hidden in the names of the characters. It does not take long to notice which of Wharton's and Segal's characters are counterparts. Though they are very similar when it comes to their behaviours and inner lives, Segal decided to give them different names that connote with Jewish history.

Wharton's Newland basically seems to stand for the new land, i.e. America (Ricard 85) and the amalgam of the old and the slowly emerging new customs that the country was in the second part of the 19th century. His surname, Archer, adds an association with a warrior. Despite his struggle, Newland does not manage to break from the confines of the society of his times. Still, he raises children who reject the clannish behaviour of the previous generation.

Adam Newman has a telling surname that suggests some kind of transition, and "possibly an allusion to an American literary type as defined by R.W.B. Lewis in The American Adam" (Singley 67). Nevertheless, even more importantly, he also has a first name with strong biblical connotations. The biblical story of Adam, if associated with progress, is rather a destructive one, the fall of the first man. Adam does not fight, he is easily seduced by Eve, here bearing the name of Ellie. As a consequence, he starts to get bored with his caring wife and to doubt the importance of family bonds, things he had not questioned before. The marriage and the family survive, but the initial enthusiasm towards life that Adam and Rachel feel at the beginning of the plot disappears.

The name of Adam's wife, Rachel, also points to the biblical tradition. Rachel was the mother of two generations of the Jewish people. Her name seems to give a promise that the final chapter of the novel does not: Adam and Rachel are actually going to have many children and grandchildren. The name of Rachel's counterpart in The Age of Innocence points to spring (Ricard 85) with its strong, inescapable potential for growth and fertility. It is an association that suggests future plenitude, just as in the case of Rachel, but it does not have any connotation with historic sources. May seems to carry a strong indication towards the new; Rachel is rooted in the distant past. 
It is also worth mentioning that at one point in the novels May and Rachel are symbolically given second names. During an archery competition, May is given the name of Diana as she makes Archer think of a Roman goddess of the hunt. The parallel passage in The Innocents describes Rachel playing Queen Esther in a performance during the celebration of the Jewish holiday, Purim. Both are at a moment when they are at the centre of attention of a group of people outside the circle of their family and friends. It is also a moment when their husbands openly state how proud of them they are and how possessive they feel about them (Wharton 211-212; Segal 281-282). Rachel takes part in a performance of a biblical story held every year on Purim, the day the Jewish people have been saved by Queen Esther from being slaughtered by Haman, the cruel advisor of a Persian king. Once again, what is suggested here is Rachel's being ingrained in Jewish tradition. The scene with the archery competition presents the graceful May as a warrior and seemingly gives the same message as in the case of Rachel: a delicate girl who is actually a warrior fighting for those she cares about most. Nonetheless, in contrast to May who is embedded in the Roman tradition, Rachel belongs to the Hebrew one. She is Jewish, and she is a mother that will protect her Jewish children: "[i]t was all there in Rachel's lovely face - a young girl unused to confrontation who, in defense of her family and her people, had found steel within" (Segal 281). She does not simply embody Queen Esther. She will become Queen Esther if the situation requires it.

It is also interesting to draw attention to the name of "Adam's father, Jacob, who had wanted nothing more than to transmit to his children a love of Jewish culture" (Segal 40). The name seems to suggest a similar sense of continuation as the name "Rachel". In the biblical tradition, Jacob was Rachel's husband and the father of the 12 tribes of Israel. The three names: Adam, Rachel, and Jacob create a sense of Jewish persistence in spite of difficulties.

\section{The titles of the novels}

Last but not least, the titles of the novels should be mentioned. The Age of Innocence points to an age that already belonged to the past in the 1920s. As V. Ricard notices, it is also ironic, as "the novel itself, set as it is in the hardly innocent years following Civil War-hardly innocent at least for those with knowledge of that war's exceptional brutality - challenges the idea that things were better once" (84). Bearing in mind the multitude of parallels in the two novels, the title of The Innocents should be ironic as well. However, what should be remembered at the same time is Segal's evident belief in the importance of family bonds and the Jewish tradition. The word "age" in the title of The Age of Innocence points to a specified time, an epoch in history. It may also stand for the age of a person or a group of people. By contrast, the title of The Innocents is less precise and, 
consequently, more universal. It clearly points to a group of people rather than one person. Moreover, it does not focus on just one epoch or the age of the characters. This universality of the title draws attention not only to the novel's central theme, which is the Jewish family in contemporary times, but also to the history of the Jewish family throughout the ages.

Considering the content of the novel, the reader has doubts whether all the characters in the book are innocent or whether this refers only to the unfortunate love triangle of Ellie, Adam, and Rachel. Is protecting the structure of a family unit against all odds an innocent purpose or is it innocent to follow one's passion even if it would threaten the structure of one's family? Bearing in mind the comparison of the coral and Adam's family, it may be suggested that the whole family is innocent of any accusations.

\section{Conclusions}

Ellie explains that her aunt's persistence in trying to keep her family and friends together is the consequence of the trauma inherited from a mother that survived the Holocaust (Segal 79-80). Yet, as the novel points out, this persistence is far from disappearing in the next generation. Singley notes that the novel "succeeds in showing readers why traditions are important by explaining that the overriding legacy of children of Holocaust survivors is an "urge to conform"' (69). It seems that the whole family suffers from a transgenerational trauma, and the lack of any chapter on the fate of the generation after Adam suggests that this situation is not going to change soon. Notwithstanding the probability of this explanation, I would like to suggest another interpretation.

Contemporary British-Jewish fiction tends to focus on family structure. At first glance, the novels seem to criticize it for its exclusiveness. Nevertheless, a closer analysis reveals that, according to these authors, maintaining the Jewish family clannish structure is, after all, an answer to the threat of cultural dispersion. It is also a milieu where one's Jewishness can be safely cherished despite the outer threat of the "new Anti-Semitism".

Segal seems to suggest that the solidarity of the Jewish family, though sometimes oppressive, is something that one should not discard easily. She demythologizes the portrait of a family unit's survival strategy that with The Age of Innocence became strongly associated with confinement. Wharton implies that further generations strive to break out of it and eventually that they do so because, at some point, the defense mechanisms of a family became no longer necessary. It was true in the case of 19th century America, but apparently not when discussing contemporary British-Jews. According to Singley, "in Segal's novel, as in Wharton's, the reader must decide whether the sacrifice of passion is worth the stability of marriage and family, but Segal more than Wharton suggests that it is" (71). The Innocents seems 
to argue that the confines of a family structure among the Jewish minority in Great Britain are still needed, as they are a shelter offering protection from cultural disappearance and that they should not and will not disappear soon.

\section{References}

Antler, J. 2007. “'My Yiddishe Mama': The Multiple Faces of the Immigrant Jewish Mother.” In: You Never Call! You Never Write! A History of the Jewish Mother. Oxford: Oxford UP, 15-45.

Evron, N. 2012. "Realism, Irony and Morality in Edith Wharton's 'The Age of Innocence.'” Journal of Modern Literature 35.2. 37-51.

Gilbert, R. 2013. "British-Jewish Writing Today.” In: Writing Jewish: Contemporary British-Jewish Literature. Basingstoke: Palgrave Macmillan, 1-18.

—. 2013. “'A Vortex of Contradictory Forces': British-Jewish Women.” In: Writing Jewish: Contemporary British-Jewish Literature. Basingstoke: Palgrave Macmillan, 122-143.

—. 2016. "Reality Gaps, Negotiating the Boundaries of British-Jewish Identities in Contemporary Fiction.” In: Diemling, M., and L. Ray (eds.). Boundaries, Identity and Belonging in Modern Judaism. New York: Routledge, 107-120.

Jessee, M. J. 2012. "Trying It On: Narration and Masking in the 'Age of Innocence." Journal of Modern Literature 36.1. 37-52.

Kahn-Harris, K., and B. Gidley. 2010. "From Jewish Continuity to Jewish Continuity.” In: Turbulent Times: The British Jewish Community Today. London: Continuum, 71-93.

—. 2012. "Contemporary Anglo-Jewish Community Leadership: Coping with Multiculturalism." The British Journal of Sociology 63.1. 168-187.

Killoran, H. 2005. "The Age of Innocence: Branching Thematic Allusions.” In: Wharton, E. The Age of Innocence. Bloom, H. (ed.). Philadelphia: Chelsea, 141-154.

Meacham, T. 1999. "An Abbreviated History of the Development of the Jewish Menstrual Laws." In: Wasserfall, R. R. (ed.). Women and Water: Menstruation in Jewish Life and Law. Hanover: Brandeis UP, 23-39.

Place, J. 1998. "Women in Film Noir.” In: Kaplan, E. A. (ed.). Women in Film Noir. London: British Film Institute, 47-68.

Plate, L. 2011. "Consuming Memories.” In: Transforming Memories in Contemporary Women's Rewriting. Basingstoke: Palgrave Macmillan, 1-34.

Ricard, V. 2017. "Reading the Age of Innocence in France." Edith Wharton Review 33.1. 84-87.

Segal, F. 2013 The Innocents. London: Vintage.

Singley, C. J. 2014. "Claire McMillan and Francesca Segal Pay Tribute to Edith Wharton's The House of Mirth and The Age of Innocence." Edith Wharton Review 30.1. 61-75.

Wharton, E. 1920. The Age of Innocence. New York: Grosset. 